\title{
Sleep and activity, age and fatness, and the energy expenditure of confined sheep
}

\author{
By P-L. TOUTAin*, Claire TOUTAIN*, A. J. F. WEBSter $\dagger$ \\ AND J. D. MCDONALD \\ Rowett Research Institute, Greenburn Road, \\ Bucksburn, Aberdeen AB2 9SB
}

(Received 21 December 1976 - Accepted 21 February 1977)

1. Changes in energy expenditure associated with sleep and activity, age and fatness were measured in sheep. States of vigilance were defined according to electrophysiological records as awake, drowsy, slowwave sleep (SWS) and paradoxical sleep (PS; Ruckebusch, 1972). Energy expenditure was determined from respiratory exchange. Three groups, each of four sheep were used; yearlings, old (4-6 years of age) fat and old thin sheep. Body fat content was estimated from deuterium oxide space.

2. The amount of time spent by sheep from each group at each state of vigilance was similar, total 'sleep' time being 200-250 min/night.

3. The absolute decrease in energy expenditure during drowsiness and sleep was similar for all groups of sheep. The difference between SWS and lying awake was $20-27 \mathrm{~J} / \mathrm{kg}$ body-weight (W) ${ }^{0.75}$ per min. Heat production was about the same for SWS and PS.

4. The energy cost of rumination was about $0.34 \mathrm{~kJ} / \mathrm{kg} \mathrm{W}$ per h.

5. The increase in heat production during standing consisted of the energy cost of standing, approximately $0.7 \mathrm{~kJ} / \mathrm{kg} \mathrm{W}$ per $\mathrm{h}$, and the energy cost of changing position, approximately $47 \mathrm{~J} / \mathrm{kg} \mathrm{W}$.

6. The old thin sheep had a slightly higher heat production on a per $\mathrm{kg}$ total $\mathrm{W}^{0.75}$ basis than the old fat sheep, but this difference largely disappeared when heat production was related to 'lean' $W$. On average energy expenditure was approximately $25 \%$ lower in the old sheep than in the yearling animals. This difference could not be related to difference in activity or in the energy costs of activity per unit of time.

Blaxter (1962) reported that the basal metabolic rate (or energy expenditure) of sheep decreased by approximately $20 \%$ between 1 and 6 years of age, while body-weight remained relatively constant. The decrease with age in the basal metabolic rate of adult humans has been reported by Durnin \& Passmore (1967), Quenouille, Boyne, Fisher \& Leitch (1951) and Webb \& Hiestand (1975), although this consensus has recently been challenged by Garrow (1974).

Measurements of basal metabolic rate in sheep were made during periods of $24 \mathrm{~h}$ (Blaxter, 1962). In this instance, the animals were deprived of food, but in more usual circumstances the $24 \mathrm{~h}$ metabolic rate of sheep confined to a calorimeter includes the energy cost to the animal of such activities as standing, eating, ruminating and grooming. The rates of energy expenditure by sheep in the clearly-defined tasks of standing and eating are known with some precision, being approximately $0.5 \mathrm{~kJ} / \mathrm{kg}$ body-weight (W) per $\mathrm{h}$ for standing and approximately $2.3 \mathrm{~kJ} / \mathrm{kg} \mathrm{W}$ per $\mathrm{h}$ for eating (see Osuji, 1974). Moreover these should be fixed costs, unlikely to change with age. Blaxter (1974) also showed that the heat production of sheep receiving a constant diet decreased by approximately $8 \%$ when they were confined continuously for $28 \mathrm{~d}$. Only approximately half this decrease could be attributed to a reduction in the amount of time the animals spent standing.

It would appear therefore that changes can occur in the energy expenditure of sheep due to age or to confinement which are unrelated to observable activity. However, using

* On leave of absence from: Ecole Nationale Vétérinaire Physiologie, 31076 Toulouse, Cédèx, France.

$\dagger$ Present address: Department of Animal Husbandry, School of Veterinary Science, University of Bristol, Bristol BS18 7DU. 
Table 1. The body-weight, deuterium oxide space and estimated body fat content of old thin, old fat and yearling sheep*

(Mean values and standard deviations)

$\begin{array}{lccccccc}\text { Group } & \overbrace{\text { Mean }}^{\text {Body-wt }(\mathrm{kg})} & \text { SD } & & \overbrace{\text { Mean }}^{\text {Dean }} & \text { SD } & & \overbrace{\text { Mean }}^{\text {Wt of fatt }(\mathbf{k g})} \\ \text { Old, thin } & 58.2 & 4.7 & & 36.0 & 4.3 & 9.8 & 0.4 \\ \text { Old, fat } & 73.0 & 6.1 & 35.5 & 1.8 & 20.2 & 5.5 \\ \text { Yearling } & 56.0 & 3.4 & & 26.5 & 3.8 & 14.0 & 1.4\end{array}$

* For details, see below.

$\dagger$ Calculated from body-weight after shearing (W) and $\mathrm{D}_{2} \mathrm{O}$ space (D): Wt of fat $=0.794 \mathrm{~W}-0.802 \mathrm{D}-$ 6.38 (Foot \& Greenhalgh, 1970).

electrophysiological records it is possible to classify the state of vigilance of a sheep more precisely into the following discrete stages; awake, drowsy, slow-wave sleep (SWS) and paradoxical sleep (PS; Ruckebusch, 1972). The amount of time that sheep spend asleep depends on the environment to which they are exposed and the extent to which they have adapted to it (Toutain \& Ruckebusch, 1973). Toutain \& Webster (1975) indicated in a short study that heat production was approximately $10-20 \%$ lower in sheep when they were asleep than when they were awake, which suggested that state of vigilance could have a significant effect on daily energy expenditure. The present paper reports an experiment designed to explore, more comprehensively, energy expenditure in sheep in relation to age, state of vigilance and to the limited range of activities performed by the confined animal.

\section{MATERIALS AND METHODS}

\section{Animals and diet}

Twelve castrated male sheep of mixed breeding (predominantly Greyface) were used. They were divided into three groups each of four animals (Table 1): old fat, sheep between 4-5 years of age weighing on average $73.0 \mathrm{~kg}$, of which approximately $3.6 \mathrm{~kg}$ was fleece; old thin, sheep between 4-6 years of age weighing on average $58.2 \mathrm{~kg}$, of which only approximately $1.5 \mathrm{~kg}$ was fleece since these sheep tended to eat their own wool; yearling, sheep aged between 14-16 months weighing on average $56.0 \mathrm{~kg}$, of which approximately $3.6 \mathrm{~kg}$ was fleece.

The thin and fat old sheep were selected by visual inspection from the stock of welltrained animals used for food-evaluation studies. All these animals had previously been confined in calorimeters on at least twenty occasions. The young sheep were given only $4 \mathrm{~d}$ of training to confinement in a respiration chamber before the experiments began. The four old thin sheep were restricted to an intake of $600 \mathrm{~g}$ chopped dried grass daily for 2 months before the start of the experiment to reduce fat content still further. At the end of the experiment the fat content of all the sheep was estimated from their deuterium oxide space using the procedure described by Foot \& Greenhalgh (1970). Table 1 shows that the old fat sheep contained approximately twice as much fat as the old thin sheep.

During the experiment each sheep was given $800 \mathrm{~g}$ dried grass pellets $/ 24 \mathrm{~h}$ in a single meal at approximately 09.00 hours. The metabolizable energy content of these pellets was about $10 \mathrm{MJ} / \mathrm{kg}$ as fed and the crude protein (nitrogen $\times 6 \cdot 25$ ) content $140 \mathrm{~g} / \mathrm{kg}$. This ration was considered to provide about enough energy and $\mathrm{N}$ for maintenance. Fresh water was available at all times. 


\section{Surgical preparations}

Electrodes for recording the electrocorticogram (ECoG), electrooculogram (EOG) and electromyogram (EMG) were inserted under general anaesthesia induced with sodium pentobarbitone and maintained with Fluothane (ICI Pharmaceuticals Division, Macclesfield). Aseptic procedures were used. The electrodes for recording ECoG and EOG were silver-coated screws attached to stainless-steel wire. Four ECoG electrodes were screwed into the skull approximately $8 \mathrm{~mm}$ each side of the mid-line and over the parietal and occipital regions of the cerebral cortex so that their tips touched the dura mater. The EOG electrodes were screwed into the temporal bone and into the lachrymal bone. The EMG electrodes were stainless-steel wires $(0.5 \mathrm{~mm}$ diameter) looped through the superficial dorsal muscles of the neck. All external connexions to the skull were reinforced and electrically insulated with denture cement.

All animals recovered rapidly after surgery and their appetites were normal within $24 \mathrm{~h}$. However, no measurements were made less than $6 \mathrm{~d}$ after operation.

\section{Measurement of heat production $(\mathrm{H})$}

$H(\mathrm{~kJ} / \mathrm{min})$ was estimated for 2 min periods from oxygen consumption $\left(\dot{V}_{\mathrm{Co}_{2}} ; \mathrm{ml} / \mathrm{min}\right)$ and carbon dioxide production $\left(\dot{V}_{\mathrm{CO}_{2}} ; \mathrm{ml} / \mathrm{min}\right)$ from the equation:

$$
H=16.18 \dot{V}_{\mathrm{O}_{2}}+5.02 V_{\mathrm{CO}_{2}} \text {. }
$$

Methane production and $\mathbf{N}$ excretion in these short periods were ignored.

Respiratory exchange was measured using an open-circuit respiration apparatus similar to that described by Webster \& Hicks (1968). The head of the sheep was enclosed in a transparent Perspex hood, 901 in volume. A collar attached to the hood was drawn quite tightly around the neck of the sheep but was sufficiently flexible to allow the animal to stand or lie at will. Since the hood was ventilated at negative pressure any small leaks around the collar were inward and did not affect the measurement of respiratory exchange. Dehumidified air was drawn through the hood at approximately $901 / \mathrm{min}$ and the response time of the apparatus was approximately $2 \mathrm{~min}$. Concentrations of respiratory gases were recorded every $35 \mathrm{~s}$ on a multipoint potentiometric recorder (Leeds and Northrup Ltd, Birmingham B11 2DJ) and other relevant measurements, ventilation rate, wet- and dry-bulb air temperature and barometric pressure, were recorded every $70 \mathrm{~s}$. When in the ventilated hood, the animal was in a room by itself but it could see out and, during the daytime, hear many of the normal sounds in the laboratory so it was not in sensory isolation. Ambient temperature was about $20^{\circ}$.

\section{Electrophysiological measurements}

These were recorded on an eight-channel polygraph (Alvar, Paris, France) at a paper speed of $36 \mathrm{~mm} / \mathrm{min}$. No filter was used and 'time' constants of $0.3 \mathrm{~s}$ for ECoG, $0.01 \mathrm{~s}$ for EMG and $1 \mathrm{~s}$ for EOG were used.

\section{Experiments}

Each sheep was continuously confined in the hood for a period of $6 \mathrm{~d}$. During the first $3 \mathrm{~d}$ no measurements were made of respiratory exchange but sleep patterns were recorded. The sheep seldom slept during their first night in the hood but nearly always showed normal sleep patterns from the second night onwards.

Beginning on the fourth evening, electrophysiological records of vigilance state, and measurements of respiratory exchange were made from approximately 18.00 hours to 09.00 hours the next morning. During this time the laboratory was quiet and the sheep 
Table 2. The duration (min) of different stages of activity and vigilance in old thin, old fat and yearling sheep* for periods of $15 \mathrm{~h}$ from 18.00 to 09.00 hours

\begin{tabular}{lcccc}
\multicolumn{1}{c}{$\begin{array}{c}\text { Group } \\
\text { Activity }\end{array}$} & Old thin & Old fat & Yearling & SE \\
$\begin{array}{l}\text { Standing } \\
\text { Lying }\end{array}$ & 356 & 294 & 191 & 39 \\
$\quad$ awake & 137 & 218 & 299 & 45 \\
$\quad$ drowsy & 152 & 183 & 166 & 21 \\
Slow-wave sleep & 209 & 163 & 192 & 23 \\
Paradoxical sleep $\dagger$ & 46 & 42 & 52 & 12 \\
& * For details, see p. 446. & & \\
& + Ruckebusch (1972).
\end{tabular}

were very relaxed. Moreover the postprandial increase in heat production after the single morning feed had largely subsided by the time that measurements began.

The following states of vigilance were distinguished: SWS, characterized by synchronized high-voltage, slow activity in ECoG with low tone in dorsal neck muscles (EMG); PS, desynchronized low-voltage, fast activity ECoG, rapid eye movements (EOG), no tone in dorsal neck muscles (EMG) but some phasic motor activity in facial muscles; awake, desynchronized low-voltage, fast activity ECoG, positive tone in neck muscles; drowsy, a combination of desynchronized low-voltage and synchronized high-voltage activity in ECoG (Ruckebusch, 1972).

Superimposed on these states of vigilance were the act of standing which could occur while the sheep was awake or drowsy, and that of rumination which occurred when the sheep was standing or lying awake, drowsy or in SWS.

The records obtained for each sheep for each night were analysed in two ways. First, the mean value for $H$ (heat production) at each stage of vigilance for each night was obtained by summing the values for $H$ and the duration of each state. Secondly, regressions were made of values for $H$ while standing awake and during SWS for each night $v$, period of time so as to examine the extent of a nychthemeral rhythm in $H$ underlying the changes in activity and state of vigilance.

\section{RESULTS}

\section{Patterns of rest and activity}

Table 2 summarizes the duration of the different states of activity and vigilance for the sheep in each group. Analyses of variance of each state revealed a significant difference between groups only in the amount of time spent standing $(P<0.05)$. The youngest sheep lay down the longest. The old fat sheep spent slightly (but not significantly) less time asleep than the other groups, but longer in the state of drowsiness so that the total amount of time spent asleep or drowsy was remarkably similar for each group at approximately $400 \mathrm{~min}$. These results show that the yearling sheep were quite as much at rest in the hood as the older animals who had 4 years of previous experience of calorimetric experiments.

The sheep all exhibited a rather regular cyclic pattern of rest and activity which persisted throughout the night. Typically each cycle began as the animal lay down. It would then become drowsy and enter SWS. A single period of SWS would last approximately $10 \mathrm{~min}$ then proceed to a period of PS lasting approximately 6 min. After two or three such periods of SWS and PS the animal would wake and usually stand up almost at once thereby concluding the cycle. A typical example of this basic rest and activity cycle is shown in 

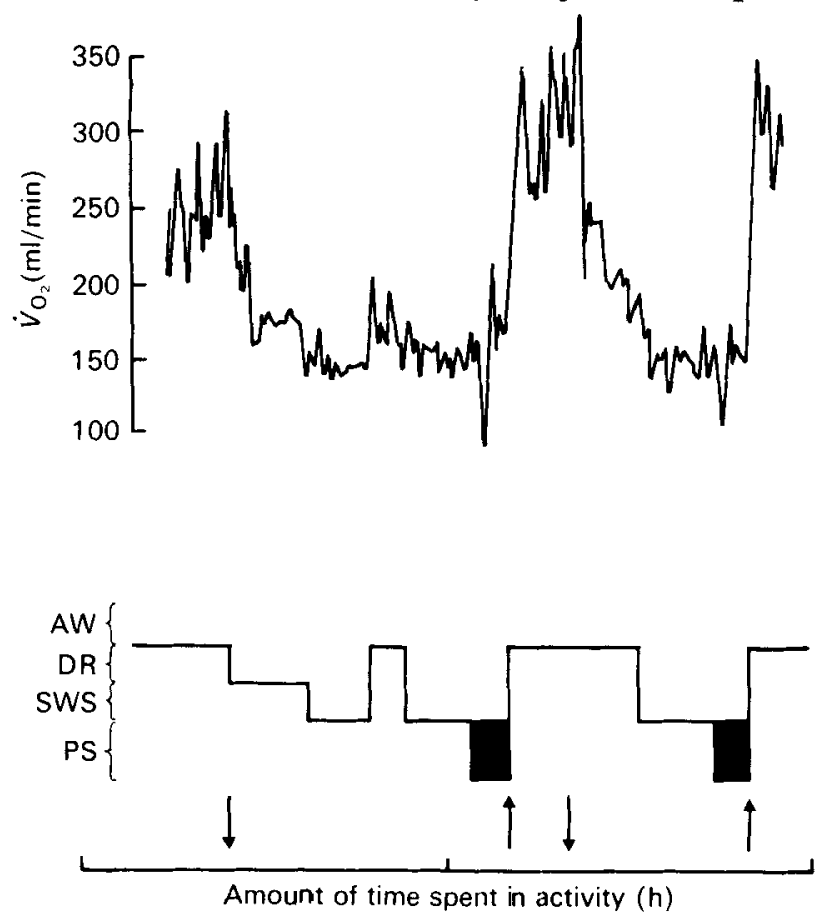

Fig. 1. Continuous record of oxygen concentration $\left(\dot{V}_{\mathrm{O}_{2}} ; \mathrm{ml} / \mathrm{min}\right)$ in the exhaust-air stream of the hood containing the head of an old fat sheep (for details, see p. 466) and ventilated at a rate of $801 /$ min (ambient rate). AW, awake; DR, drowsy; SWS, slow-wave sleep; PS, paradoxical sleep (Ruckebusch, 1972); standing up, ( $\uparrow$ ): lying down, $(\downarrow)$ (for details of states of vigilance, see p. 448).

Fig. 1. The amount of time the sheep remained standing during any one cycle was short, approximately $14 \mathrm{~min}$ and the average duration of a complete rest and activity cycle was approximately $60 \mathrm{~min}$.

\section{Vigilance and $H$ (heat production)}

Typical changes in respiratory exchange associated with changes in state of vigilance are illustrated in Fig. 1. $\mathrm{O}_{2}$ consumption and $\mathrm{CO}_{2}$ production decreased as the sheep lay down and decreased further as drowsiness proceeded to SWS. During PS, respiration depth and frequency were very irregular and this variability was reflected in respiratory exchange. The decrease in $\mathrm{O}_{2}$ consumption with increasing somnolence was always greater than that of $\mathrm{CO}_{2}$ production and the respiratory quotient increased on average from approximately 1.09 when the sheep were standing awake to approximately 1.20 during SWS. Presumably this was at least in part because the contribution of rumen fermentation to $\mathrm{CO}_{2}$ production remained constant throughout.

Mean values for $H$ for each group of sheep at each state of vigilance appear in Table 3. A 'split-plot' analysis of variance of these results, taking sheep as 'main plots' and state of vigilance as 'subplots' revealed a significant difference in $H$ between groups of sheep $(F 6.9, P<0.05)$ and a very highly significant effect of state of vigilance $(F 646, P<0.001)$. The nature of the 'split-plot' design is that, compared to a randomized-block design, it confers increased precision on 'subplots' (state of vigilance) at the expense of precision on 'main plots' (groups of sheep) (Cochran \& Cox, 1957). Weighted mean values for $H$ in the $15 \mathrm{~h}$ periods of the experiment were $\left(\mathrm{J} / \mathrm{kg} \mathrm{W}^{0.75}\right.$ per min): 268 yearling sheep, 215 old thin sheep, 180 old fat sheep. Values for $H$ differed significantly between all states of 
Table 3. Heat production ( $H, J / k g W^{0.75}$ per min), and difference in $H$ from lying awake $(\Delta \mathrm{H})$, of old thin, old fat and yearling sheep* while standing or lying awake, drowsy, in slowwave sleep or paradoxical sleep $\dagger$

\begin{tabular}{|c|c|c|c|c|c|c|}
\hline \multirow{2}{*}{$\underset{\text { Activity }}{\text { Group }} \ldots$} & \multicolumn{2}{|c|}{ Old thin } & \multicolumn{2}{|c|}{ Old fat } & \multicolumn{2}{|c|}{ Yearling } \\
\hline & $H$ & $\Delta H$ & $H$ & $\Delta H$ & $H$ & $\Delta H$ \\
\hline $\begin{array}{l}\text { Standing awake } \\
\text { Lying }\end{array}$ & 254 & +47 & 221 & +50 & 320 & +54 \\
\hline awake & 207 & - & 171 & - & 266 & - \\
\hline drowsy & 189 & -18 & 157 & -14 & 250 & -16 \\
\hline Slow-wave sleep & 180 & -27 & 151 & -20 & 245 & -21 \\
\hline Paradoxical sleep & 180 & -27 & 148 & -23 & 239 & -27 \\
\hline Weighted mean value $\ddagger$ & 215 & - & 180 & - & 268 & - \\
\hline
\end{tabular}

SE of differences: between groups $25 \cdot 8$, between states of vigilance $2 \cdot 2$.

W, body-weight.

* For details, see p. 446.

$\dagger$ Ruckebusch (1972).

$\ddagger H$ at each stage of vigilance $\times$ duration of each state of vigilance (see Table 2).

Table 4. Changes with time $(t)$ in values observed for heat production $(\mathrm{H}, k J / m i n)$ for old thin, old fat and yearling sheep* during slow-wave sleep (SWS) and while standing awake (St awake)

\begin{tabular}{|c|c|c|c|c|c|c|c|}
\hline \multirow[b]{2}{*}{ Group } & \multirow[b]{2}{*}{ Activity } & \multicolumn{2}{|c|}{$\begin{array}{l}\text { Equation: } \\
H_{t}=H_{0} \mathrm{e}^{-k t}\end{array}$} & & \multicolumn{3}{|c|}{$\begin{array}{l}H\left(\mathrm{~kJ} / \mathrm{kg} \mathrm{W} \mathrm{W}^{0.75} \text { per min) at }\right. \\
\text { various values for } t(\mathrm{~min})\end{array}$} \\
\hline & & $H_{0}$ & $-k\left(\times 10^{-3}\right)$ & & 0 & 450 & 900 \\
\hline Old thin & $\begin{array}{l}\text { SWS } \\
\text { St awake }\end{array}$ & $\begin{array}{l}4 \cdot 72 \\
6 \cdot 27\end{array}$ & $\begin{array}{l}0 \cdot 246 \\
0 \cdot 275\end{array}$ & $\Delta H$ & $\begin{array}{r}213 \\
284 \\
71\end{array}$ & $\begin{array}{r}191 \\
250 \\
59\end{array}$ & $\begin{array}{r}171 \\
221 \\
50\end{array}$ \\
\hline Old fat & $\begin{array}{l}\text { SWS } \\
\text { St awake }\end{array}$ & $\begin{array}{l}4 \cdot 36 \\
6 \cdot 61\end{array}$ & $\begin{array}{l}0 \cdot 132 \\
0 \cdot 187\end{array}$ & $\Delta H$ & $\begin{array}{r}166 \\
252 \\
86\end{array}$ & $\begin{array}{r}157 \\
233 \\
76\end{array}$ & $\begin{array}{r}148 \\
213 \\
65\end{array}$ \\
\hline Yearling & $\begin{array}{l}\text { SWS } \\
\text { St awake }\end{array}$ & $\begin{array}{l}5 \cdot 73 \\
7 \cdot 13\end{array}$ & $\begin{array}{l}0.208 \\
0.256\end{array}$ & $\Delta H$ & $\begin{array}{r}277 \\
344 \\
67\end{array}$ & $\begin{array}{r}252 \\
307 \\
55\end{array}$ & $\begin{array}{r}229 \\
273 \\
44\end{array}$ \\
\hline
\end{tabular}

$t$, time elapsed (min) after 18.00 hours; $H_{t}, H_{0}$, values for $H\left(\mathrm{~kJ} / \mathrm{kg} \mathrm{W} W^{0.75}\right.$ per min) at $t$ and $t=0$ respectively; $\Delta H$, differences between derived values for $H$ when standing awake and during SWS; W, bodyweight.

* For details see p. 446.

vigilance except SWS and PS for old thin and old fat sheep. For yearling sheep, these two states did differ significantly $(P<0.05)$. There was no suggestion of an interaction between groups and states of vigilance $(F 0.5)$, i.e. changes in $H$ associated with changing state of vigilance were very similar for all groups.

The increase in $H$ during standing compared with lying awake was $47-54 \mathrm{~J} / \mathrm{kg} \mathrm{W}^{0.75}$ per $\min$, or $1.01-1 \cdot 18 \mathrm{~kJ} / \mathrm{kg} \mathrm{W}$ per $\mathrm{h}$. The difference between SWS and lying awake was 20-27 J/kg W ${ }^{0.75}$ per min. Because the yearling sheep had a higher $H$ than the older sheep while lying awake, the relative decrease in $H$ during SWS was only $7.8 \%$ compared with $11.7 \%$ for the old fat sheep and $13.0 \%$ for the old thin sheep.

\section{Nychthemeral rhythm of $\mathrm{H}$ (heat production)}

Changes in $H$ associated with changing state of vigilance took place about mean values that decreased significantly throughout the period of measurement from 18.00 hours to 
09.00 hours. Table 4 expresses the decrease in $H$ during SWS and while standing awake in the form of exponential equations and gives predicted values of $H$ at time $(t)=0,450$ and 900 (18.00, 01.30 and 09.00 hours respectively). The decrease through the night in $H$ while standing was, on average $58 \mathrm{~kJ} / \mathrm{kg} \mathrm{W}^{0.75}$ per min (approximately $20 \%$ ), and during SWS it was, on average, $36 \mathrm{~kJ} / \mathrm{kg} \mathrm{W}^{0.75}$ per min (approximately $16 \%$ ), thus the absolute and relative difference in $H$ between SWS and standing awake also apparently decreased during the night. This apparent difference could be due, in part, to the form of the exponential equations used but Table 4 does suggest that not only did mean $H$ decrease during the night, so too did the absolute variations about the mean due to changes in state of vigilance. Predicted values for $H$ at $450 \mathrm{~min}$ were very similar to the mean values, uncorrected for nychthemeral changes, that were given in Table 3 . Since the pattern of rest and activity in the sheep was polyphasic (i.e. periods of standing, lying and sleep were spread fairly evenly through the night) the uncorrected values for $H$ given in Table 3 should represent accurately the mean changes in $H$ due to changing state of vigilance, although it appears that these values are not absolutes, they too are subject to a nychthemeral rhythm.

\section{Rumination}

The dried grass given to the sheep was ground and pelleted for convenience of feeding while the animals were kept in the ventilated hood. The amount of time they spent ruminating this diet was only approximately $2 \mathrm{~h} / \mathrm{night}$, which was similar to that observed previously (Osuji, Gordon \& Webster, 1975). The sheep were observed to ruminate while standing awake, lying awake, drowsy and in SWS. However, often sheep would begin or end a period of rumination as they changed their state of vigilance, e.g. from drowsiness to SWS, so it was often impossible to dissociate changes in $H$ due to rumination from changes due to changing state of vigilance. From the 2 min measurements of $H$ where sheep began and ended a period of rumination within a single state of vigilance, the following mean values were obtained for the energy cost of rumination $(\mathrm{kJ} / \mathrm{kg} \mathrm{W}$ per $\mathrm{h})$ :

$\begin{array}{lcc}\text { State of vigilance } & \text { Mean } & \text { SE } \\ \text { Standing awake } & 0.36 & 0.06 \\ \text { Lying awake } & 0.34 & 0.05 \\ \text { Lying drowsy } & 0.33 & 0.07 \\ \text { SWS } & 0.30 & 0.08\end{array}$

Most values were obtained while the sheep were lying awake and the standard error of the mean, $0.34 \mathrm{~kJ} / \mathrm{kg} \mathrm{W}$ per $\mathrm{h}$, reflected this. There were no significant differences in the energy cost of ruminating between the different states of vigilance, but there is a suggestion that the energy cost was least during SWS.

\section{DISCUSSION}

\section{Energy cost of standing}

The average difference of $1.01-1 \cdot 18 \mathrm{~kJ} / \mathrm{kg} \mathrm{W}$ per $\mathrm{h}$ in $H$ for sheep between standing and lying awake is approximately twice that of $0.5 \mathrm{~kJ} / \mathrm{kg} \mathrm{W}$ per h given by Osuji (1974) in his comprehensive review of measurements made of the energy cost of standing in sheep. The values in Table 3 include the energy cost of changing position and during the period that measurements were made the sheep only remained standing on average for $10-15 \mathrm{~min}$ at a time. Individual records showed that $H$ was greatest just after the sheep stood up then tended to decrease. In order to separate the energy cost of standing from the cost of changing position regressions were derived for the values obtained for the energy cost 
of standing $\left(H_{i} ; \mathrm{kJ} / \mathrm{kg} \mathrm{W}\right.$ per $\left.\mathrm{h}\right)$ for periods from 2 to $40 \mathrm{~min} v$. amount of time spent standing (min). This revealed an exponential decrease in $H_{s}$ with time $(t)$ :

$$
H_{s}=1 \cdot 32 e^{-0 \cdot 0162 t} .
$$

This equation predicted $H_{s}$ during the first 2 min spent standing to be 1.30 and that at $40 \mathrm{~min}$ to be $0.69 \mathrm{~kJ} / \mathrm{kg} \mathrm{W}$ per h, but cannot be extrapolated sensibly beyond the observed amounts of times spent standing. The value of 0.69 is quite close to that preferred by Osuji (1974). It was not possible to separate precisely the energy cost of rising to a standing position from that of other activities such as drinking, urinating or investigatory behaviour that sheep engage in immediately after awakening from PS and standing up. However, mean $H_{s}$ during the first 5 min of standing was $1.26 \mathrm{~kJ} / \mathrm{kg} \mathrm{W}$ per h. The difference between this value and the energy cost of standing after $40 \mathrm{~min}$ was 0.57 which suggested that the sheep expended an extra $47 \mathrm{~J} / \mathrm{kg} \mathrm{W}$ in the first 5 min that they were on their feet. This could, as a first approximation, be called the energy cost of rising to a standing position. Hall \& Brody (1933) using a rather similar approach obtained a rather similar value of $52 \mathrm{~J} / \mathrm{kg}$ for the energy cost of rising to a standing position for cattle.

\section{Energy cost of rumination}

The average value for the energy cost of rumination was about $0.33 \mathrm{~kJ} / \mathrm{kg} \mathrm{W}$ per h. Previous estimates have been 1.00 (Graham, 1965), 0.11 (Osuji et al. 1975) and 1.09 (Davey \& Holmes, 1977). Only in the last instance was the response time of the respiration apparatus comparable to that in the present experiments, and in no instance were changes in $H$ during rumination distinguished from changes in state of vigilance.

The present value for the energy cost of ruminating was only approximately $15 \%$ of the energy cost of eating $(2 \cdot 1-2 \cdot 6 \mathrm{~kJ} / \mathrm{kg} \mathrm{W}$ per h; Osuji et al. 1975). The maximum amount of time spent ruminating by sheep, given an unchopped, highly-fibrous diet, is approximately $8 \mathrm{~h} / \mathrm{d}$ (Gordon, 1968). Even in this extreme instance, the total energy cost of rumination would only be $132 \mathrm{~kJ} / 24 \mathrm{~h}$, or approximately $2 \%$ of the daily value for $H$ for an animal in energy balance. There is therefore no reason to suppose, as has been claimed by Hogan, Weston \& Lindsay (1969), that the energy cost of ruminating could make a substantial direct contribution to the high heat increment of fibrous foods.

\section{Sleep and energy expenditure}

On average, $H$ was approximately $10 \%$ lower during SWS and PS than when the sheep were lying awake, and the difference was much the same for yearling and older sheep, although the yearling sheep were less thoroughly trained and had over all a significantly greater rate of $H$. Assuming that both yearling and older sheep were equally relaxed when asleep one must also assume that they were equally relaxed while awake (see Ruckebusch, 1975).

In our previous short study with two young Friesian calves and two adult sheep, the difference in $H$ between lying awake and SWS was approximately $10 \%$ for calves but more than $20 \%$ for sheep (Toutain \& Webster, 1975). The sheep in this former experiment were noticeably apprehensive while awake and we attributed the apparent difference between the species to this. The present experiment reinforces the conclusion that $H$ differs by approximately $10 \%$ between sleep and lying awake for ruminants when animals are totally relaxed.

Comparison between these results and those recorded from man are not easy because in nearly all the experiments reviewed by Webb \& Hiestand (1975) no values are reported from the subjects while lying awake. Nevertheless the present results support the observation of Webb \& Hiestand (1975) that there is no difference in $H$ between SWS and PS. Brebbia 
\& Altshuler (1965) had earlier claimed that $\mathrm{O}_{2}$ consumption in man was higher during PS than in other stages of sleep. Wallace, Benson \& Wilson (1971) have reported a wakeful hypometabolic state in man; a reduction of approximately $15 \%$ in $\mathrm{H}$ during transcendental meditation. In energetic terms, at least, such a state would appear to have much the same effect in man as does falling asleep in the sheep.

Housed, undisturbed sheep sleep approximately $4 \mathrm{~h}$ in each $24 \mathrm{~h}$ (Ruckebusch, 1972). Out-of-doors, this period is slightly reduced. If sheep, for some reason, were prevented from sleeping at all, the direct effect on energy expenditure would be an increase of less than $2 \%$. It would, of course, be expected that an environment sufficiently disturbing to prevent a sheep from sleeping at all would also increase its level of vigilance and probably its energy expenditure while awake although its extent cannot be stated. Nevertheless it is most unlikely that differences in the duration of sleep per se could make a significant contribution to differences in energy expenditure between housed and grazing animals. Nor can these differences explain fully the decrease of $8 \%$ observed by Blaxter (1974) in values for $H$ of sheep as they adapted to prolonged confinement.

\section{Age, fatness and energy expenditure}

The decrease with age in the energy expenditure of the sheep in the present experiments was very similar to that reported by Blaxter (1962). Estimated energy requirements for maintenance of energy balance $\left(\mathrm{kJ} / \mathrm{kg} \mathrm{W}^{0.75}\right.$ per $\left.24 \mathrm{~h}\right)$ at 1 year and approximately 5 years of age are respectively 366, 302 (Blaxter, 1962); 386, 284 (present experiment).

When the mean values for $H$ in yearling, old fat and old thin sheep (Table 3 ) were recalculated on the basis of fat-free W [W - (fleece + body fat)], values obtained were 353,237 and $250 \mathrm{~J} / \mathrm{kg} \mathrm{W}^{0.75}$ per min, which suggests that the difference between the fat and thin old sheep was largely due to the fact that fat is less active metabolically than lean tissue. In this context 'old' indicated sheep of 4-6 years of age, and no anthropomorphic comparison was intended. Nevertheless it is clear that the older sheep had a markedly lower $H$ than the yearling animals but this difference appeared to be unrelated to behaviour. The young and old sheep spent approximately the same amount of time asleep, and the young animals tended to spend a longer period of time lying down. Moreover, differences in $H$ associated with different states of vigilance were the same in yearling and older animals implying, as indicated previously, that both groups were equally relaxed. Thus the greater $\boldsymbol{H}$ of the yearlings cannot be attributed to any stress imposed by the unusual environment to which they were exposed or to differences in spontaneous activity between youth and age.

The authors acknowledge the assistance of R. N. B. Kay and L. E. Vowles in the surgical preparation of these animals. P. L. Toutain and Claire Toutain were supported in part by a grant from the Underwood Fund.

\section{REFERENCES}

Blaxter, K. L. (1962). Br. J. Nutr. 16, 615.

Blaxter, K. L. (1974). Publs Eur. Ass. Anim. Prod. no. 14, 115.

Brebbia, D. R. \& Altshuler, K. Z. (1965). Science, N.Y. 150, 1621.

Cochran, W. G. \& Cox, G. M. (1957). Experimental designs, 2nd ed. p. 296. London: Wiley.

Davey, A. W. F. \& Holmes, C. W. (1977). Anim. Prod. 24, 355.

Durnin, J. V. G. A. \& Passmore, R. (1967). Energy, Work and Leisure. London: Heinemann.

Foot, J. Z. \& Greenhalgh, J. F. D. (1970). Br. J. Nutr. 24, 815.

Garrow, J. S. (1974). Energy Balance and Obesity in Man. London: North Holland Publications.

Gordon, J. G. (1968). Wld Rev. Nutr. Diet. 9, 251.

Graham, N. McC. (1965). Publs Eur. Ass. Anim. Prod. no. 11, 231.

Hall, W. C. \& Brody, S. (1933). Univ. Mo. agric. Exp. Stn. Res. Bull. no. 180. 
Hogan, J. P., Weston, R. H. \& Lindsay, J. R. (1969). Aust. J. agric. Res. 20, 925.

Osuji, P. O. (1974). J. Range Mgt 27, 437.

Osuji, P. O., Gordon, J. G. \& Webster. A. J. F. (1975). Br. J. Nutr. 34, 59.

Quenouille, M. H., Boyne, A. W., Fisher, W. B. \& Leitch, I. (1951). Tech. Commun. Bur. Anim. Nutr., Aberd., no. 17.

Ruckebusch, Y. (1972). Anim. Behav. 20, 637.

Ruckebusch, Y. (1975). Appl. Anim. Ethology 2, 3.

Toutain, P-L. \& Ruckebusch, Y. (1973). C. r. Soc. Biol. 167, 550.

Toutain, P-L. \& Webster, A. J. F. (1975). C. r. Acad. Sci., Paris, D, 1605.

Wallace, R. K., Benson, H. \& Wilson, A. F. (1971). Am. J. Physiol. 221, 795.

Webb, P. \& Hiestand, M. (1975). J. appl. Phvsiol. 38, 257.

Webster, A. J. F. \& Hicks, A. M. (1968). Can. J. Anim. Sci. 48, 89. 